\title{
Genetic testing for Marfan syndrome
}

\author{
Yeltay Rakhmanov ${ }^{1}$, Paolo Enrico Maltese ${ }^{1 \star}$, Carla Marinelli ${ }^{1}$, Marco Castori $^{2}$, Tommaso Beccari ${ }^{3}$, \\ Munis Dundar ${ }^{4}$ and Matteo Bertelli ${ }^{1,5}$
}

\begin{abstract}
Marfan syndrome (MFS) is an inherited connective tissue disorder caused by heterozygous mutations in the FBN1 gene. Clinical manifestations of MFS include aortic dilatation and dissection, as well as cardiac valvular, ocular, skeletal and neurological manifestations. Prevalence varies from 6 to 20 per 100,000 individuals. Revised Ghent Nosology (2010) is used to establish a clinically based suspected diagnosis to be confirmed by molecular testing. This Utility Gene Test was prepared on the basis of an analysis of the literature and existing diagnostic protocols. Molecular testing is useful for diagnosis confirmation, as well as differential diagnosis, appropriate genetic counselling and access to clinical trials.
\end{abstract}

Keywords: Marfan syndrome, FBN1, EBTNA UTILITY GENE TEST

'MAGI's Lab, Rovereto, Italy

${ }^{2}$ Division of Medical Genetics, IRCCS-Casa Sollievo della Sofferenza, San Giovanni

\section{Rotondo (FG), Italy}

${ }^{3}$ Department of Pharmaceutical Sciences, University of Perugia, Perugia, Italy

${ }^{4}$ Department of Medical Genetics, Erciyes University Medical School, Kayseri, Turkey ${ }^{5}$ MAGI Euregio, Bolzano, Italy

*Corresponding author: P. E. Maltese E-mail: paolo.maltese@assomagi.org

DOI: 10.2478/ebtj-2018-0032
(C) 2018 Authors. This work was licensed under the Creative Commons AttributionNonCommercial-NoDerivs 3.0 License.

\section{Marfan syndrome}

(other synonyms: Marfan syndrome type 1)

\section{General information about the disease}

Marfan syndrome (MFS, OMIM disease 154700) is an inherited connective tissue disorder caused by heterozygous mutations in the extracellular matrix protein fibrillin 1 (FBN1). Cardinal manifestations of MFS include aortic aneurysm, lens dislocation and long-bone overgrowth (1). A multidisciplinary approach is required for patient management. Aortic dilatation and dissection are the major issues, while cardiac valvular, ocular, skeletal and neurological involvement are significant complications (2). Periodic monitoring for aortic dilation is necessary to prevent progression to aortic dissection (3). Pharmacological strategies should be considered to reduce blood pressure to slow down the process of aortic dilation. Today a combination of drugs, aortic monitoring and heart surgery ensure MFS patients a similar life expectancy to that of healthy people (4). Surgery may also be useful for eye and skeletal anomalies.

Since MFS may present with clinical manifestations of varying severity, diagnosis is often delayed. Undiagnosed patients can have serious complications and are at risk of sudden death, usually due to aortic dissection.

Estimated prevalence of MFS is from 6 to 20 per 100,000 individuals (5). Sun et al. (6) reported a prevalence of 17.2 per 100,000 in China in 1990.

The Revised Ghent Nosology (2010) is used to diagnose MFS. It divides diagnostic manifestations into "major" and "minor" criteria. The Ghent criteria were modified when mutations in FBN1 (OMIM gene 134797) were found to cause MFS. Patients without a family history of the disease, but with a "major criterion" in at least two organs and involvement of a third organ system (i.e. at least one "minor criterion") are clinically diagnosed with MFS. Patients carrying a heterozygous mutation in FBN1 or with a positive family history, must have one major criterion and involvement of an additional 
organ to be diagnosed with $\operatorname{MFS}(7,8)$. The following multiple diagnostic modalities and methods are regularly used to diagnose MFS: clinical examination and history, heart ultrasound, eye examination with slit lamp for lens dislocation, advanced imaging studies of the vascular tree, and genetic testing for mutations in FBN1.

The differential diagnosis should consider Loeys-Dietz syndromes, congenital contractural arachnodactyly/Beals syndrome, non-syndromic familial thoracic aortic disease, Ehlers-Danlos syndromes, homocystinuria caused by cystathionine $\beta$-synthase deficiency, Stickler syndrome and fragile X syndrome.

MFS has autosomal dominant inheritance. Approximately $75 \%$ of individuals with MFS have an affected parent and approximately $25 \%$ have a de novo pathogenic variant in FBN1 (9).

Pathogenic variants may include missense, nonsense, small insertions, small deletions, small indels and gross deletions (10).

\section{Aims of the test}

- To determine the gene defect responsible for the disease;

- To confirm clinical diagnosis;

- To assess the recurrence risk and perform genetic counselling for at-risk/affected individuals.

\section{Test characteristics}

\section{Specialist centers/ Published Guidelines}

The test is listed in the Orphanet database and is offered by 44 accredited medical genetic laboratories in the EU, and in the GTR database, offered by 28 accredited medical genetic laboratories in the US.

Guidelines for clinical use of the test are described in Genetics Home Reference (ghr.nlm.nih.gov) and Gene Reviews (9).

\section{Test strategy}

In patients meeting the revised Ghent criteria and after exclusion of partially overlapping disorders, we advise Sanger sequencing for the detection of nucleotide variations in coding exons and flanking introns in the FBN1 gene. Sanger sequencing is also used for family segregation studies.

Multiplex Ligation Probe Amplification (MLPA) is used to detect duplications and deletions in FBN1.

In incomplete phenotypes that only meet some of the revised Ghent criteria or overlapping phenotypes with mixed features of MFS and other Marfan-like conditions, a wider approach with next generation resources (e.g. customized gene panels or exome analysis) may be considered in highly specialized settings.

To perform molecular diagnosis, a single sample of biological material is normally sufficient. This may be $1 \mathrm{ml}$ peripheral blood in a sterile tube with $0.5 \mathrm{ml} \mathrm{K}$ EDTA or $1 \mathrm{ml}$ saliva in a sterile tube with $0.5 \mathrm{ml}$ ethanol $95 \%$. Sampling rarely has to be repeated.

Gene-disease associations and the interpretation of genet- ic variants are rapidly developing fields. It is therefore possible that the genes mentioned in this note may change as new scientific data is acquired. It is also possible that genetic variants today defined as of "unknown or uncertain significance" may acquire clinical importance.

\section{Genetic test results \\ Positive}

Identification of a pathogenic variant in the FBN1 gene confirms the clinical diagnosis and is an indication for family studies.

A pathogenic variant is known to be causative for a given genetic disorder based on previous reports, or predicted to be causative based on loss of protein function or expected significant damage to proteins or protein/protein interactions. In this way it is possible to obtain a molecular diagnosis in new/other subjects, establish the risk of recurrence in family members and plan preventive and/or therapeutic measures.

\section{Inconclusive}

Detection of a variant of unknown or uncertain significance (VUS): a new variation without any evident pathogenic significance or a known variation with insufficient evidence (or with conflicting evidence) to indicate it is likely benign or likely pathogenic for a given genetic disorder. In these cases, it is advisable to extend testing to the patient's relatives to assess variant segregation and clarify its contribution. In some cases, it could be necessary to perform further examinations/tests or to do a clinical reassessment of pathological signs.

\section{Negative}

The absence of variations in the genomic regions investigated does not exclude a clinical diagnosis but suggests the possibility of:

- alterations that cannot be identified by sequencing, such as large rearrangements that cause loss (deletion) or gain (duplication) of extended gene fragments;

- sequence variations in gene regions not investigated by this test, such as regulatory regions (5' and 3' UTR) and deep intronic regions;

- variations in other genes not investigated by the present test.

\section{Unexpected}

Unexpected results may emerge from the test, for example information regarding consanguinity, absence of family correlation or other genetically based diseases.

\section{Risk for progeny}

In autosomal dominant transmission, the probability that an affected carrier transmit the variant to his/her children is $50 \%$ in any pregnancy, irrespective of the sex of the child conceived.

\section{Limits of the test}

The test is limited by current scientific knowledge regarding the gene and disease. 
Analytical sensitivity (proportion of positive tests when the genotype is truly present) and specificity (proportion of negative tests when the genotype is not present)

SANGER Analytical sensitivity $>99.99 \%$; Analytical specificity $99.99 \%$.

MLPA Analytical sensitivity $>99.99 \%$; Analytical specificity $99.99 \%$.

Clinical sensitivity (proportion of positive tests if the disease is present) and clinical specificity (proportion of negative tests if the disease is not present)

Clinical sensitivity: high variable expressivity has been reported in FBN1 mutations and the clinical sensibility is higher when patients fulfilled the Ghent criteria.

Clinical specificity: data not available.

\section{Prescription appropriateness}

The genetic test is appropriate when:

a) the patient meets the diagnostic criteria for MFS;

b) the sensitivity of the test is greater than or equal to that of tests described in the literature.

\begin{tabular}{|l|c|}
\hline Clinical utility \\
\hline Clinical management & Utility \\
\hline Confirmation of clinical diagnosis & Yes \\
\hline Differential diagnosis & Yes \\
\hline Couple risk assessment & Yes \\
\hline
\end{tabular}

Availability of clinical trials can be checked on-line at https://clinicaltrials.gov/

\section{References}

1. Judge DP, Dietz HC. Marfan's syndrome. Lancet 2005; 366(9501): 1965-1976.

2. Radke RM, Baumgartner H. Diagnosis and treatment of Marfan syndrome: an update. Heart 2014; 100(17): 1382-1391.
3. Hiratzka LF, Bakris GL, Beckman JA, Bersin RM, Carr VF, Casey DE Jr, Eagle KA, Hermann LK, Isselbacher EM, Kazerooni EA, Kouchoukos NT, Lytle BW, Milewicz DM, Reich DL, Sen S, Shinn JA, Svensson LG, Williams DM; American College of Cardiology Foundation/American Heart Association Task Force on Practice Guidelines; American Association for Thoracic Surgery; American College of Radiology; American Stroke Association; Society of Cardiovascular Anesthesiologists; Society for Cardiovascular Angiography and Interventions; Society of Interventional Radiology; Society of Thoracic Surgeons; Society for Vascular Medicine. ACCF/AHA/AATS/ACR/ASA/ SCA/SCAI/SIR/STS/SVM Guidelines for the diagnosis and management of patients with thoracic aortic disease. A Report of the American College of Cardiology Foundation/American Heart Association Task Force on Practice Guidelines, American Association for Thoracic Surgery, American College of Radiology, American Stroke Association, Society of Cardiovascular Anesthesiologists, Society for Cardiovascular Angiography and Interventions, Society of Interventional Radiology, Society of Thoracic Surgeons, and Society for Vascular Medicine. Circulation 2010;121(13): e266-369.

4. Silverman DI, Burton KJ, Gray J, Bosner MS, Kouchoukos NT, Roman MJ, Boxer M, Devereux RB, Tsipouras P. Life expectancy in the Marfan syndrome. Am J Cardiol; 75(2): 157-60.

5. Groth KA, Hove H, Kyhl K, Folkestad L, Gaustadnes M, Vejlstrup N, Stochholm K, Østergaard JR, Andersen NS, Gravholt CH. Prevalence, incidence, and age at diagnosis in Marfan Syndrome. Orphanet J Rare Dis 2015; 10: 153.

6. Sun QB, Zhang KZ, Cheng TO, Li SL, Lu BX, Zhang ZB, Wang W. Marfan syndrome in China: a collective review of 564 cases among 98 families. Am Heart J 1990; 120(4): 934-48.

7. Von Kodolitsch Y, Robinson PN. Marfan syndrome: an update of genetics, medical and surgical management. Heart 2007; 93(6): 755-60.

8. Brennan P. Revised diagnostic criteria for Marfan syndrome. J R Coll Physicians Edinb 2011; 41(3): 223.

9. Dietz H. Marfan Syndrome. In: MP Adam, HH Ardinger, RA Pagon, SE Wallace, LJH Bean, et al., editors. GeneReviews(R) 1993; Seattle (WA).

10. Faivre L, Collod-Beroud G, Loeys BL, Child A, Binquet C, Gautier E, Callewaert B, Arbustini E, Mayer K, Arslan-Kirchner M, Kiotsekoglou A, Comeglio P, Marziliano N, Dietz HC, Halliday D, Beroud C, Bonithon-Kopp C, Claustres M, Muti C, Plauchu H, Robinson PN, Adès LC, Biggin A, Benetts B, Brett $M$, Holman KJ, De Backer J, Coucke P, Francke U, De Paepe A, Jondeau G, Boileau C. Effect of mutation type and location on clinical outcome in 1,013 probands with Marfan syndrome or related phenotypes and FBN1 mutations: an international study. Am J Hum Genet 2007; 81(3): 454-66. 